\title{
Influence of Crevice Thickness on Corrosion Behavior of API X80 Steel under Disbonded Coating in Acid Soil Environment
}

\author{
Bo Zhao ${ }^{1,3}$, Hongxia Wan $^{2}$, Yunyan Peng ${ }^{1}$, Chao Liu ${ }^{3}$, Jun Li $^{1, *}$, Binan Shou ${ }^{1}$ \\ ${ }^{1}$ Institute of Chemical Analysis, China Special Equipment Inspection and Research Institute, Beijing \\ 100029, China. \\ ${ }^{2}$ Beijing Key Laboratory of Failure, Corrosion and Protection of Oil/Gas Facility Materials, \\ Department of Materials Science and Engineering, China University of Petroleum (Beijing), Beijing \\ 102249, China. \\ ${ }^{3}$ Key Laboratory for Corrosion and Protection (MOE), Institute for Advanced Materials and \\ Technology, University of Science and Technology Beijing, 100083, China. \\ *E-mail: zhaobo19840626@163.com
}

doi: $10.20964 / 2021.01 .19$

Received: 6 August 2020 / Accepted: 28 September 2020 / Published: 30 November 2020

In this study, an experimental device based on the disbonded coating model for the Yingtan simulated soil solution has been developed. The corrosion behavior of X80 steel was studied by anodic polarization, electrochemical impedance spectroscopy (EIS) and scanning electron microscopy (SEM).The observed findings showed that the anodic polarization demonstrated "passivation" behavior when the crevice thickness was about $35 \mu \mathrm{m}$. However, the anodic current density increased and anode active dissolution tendency was sobered to enhance with the thickness. The charge transfer resistance (Rt) achieved the minimum and maximum values at a thickness of $150 \mu \mathrm{m}$ and $400 \mu \mathrm{m}$ respectively. The corrosion effects was noted to be serious at a thickness of $150 \mu \mathrm{m}$, and the pitting appeared due to the enhanced amounts of $\mathrm{O}_{2}$ and $\mathrm{H}^{+}$migrating in the disbonded area, which was consistent with the findings from EIS.

Keywords: X80 steel, Disbonded coating, Soil environment, Crevice corrosion, Corrosion Behavior

\section{$\underline{\text { FULL TEXT }}$}

(C) 2021 The Authors. Published by ESG (www.electrochemsci.org). This article is an open access article distributed under the terms and conditions of the Creative Commons Attribution license (http://creativecommons.org/licenses/by/4.0/). 